Artigo original

\title{
Estudo comparativo de um protocolo de terapia manual aplicado em pacientes com síndrome dolorosa miofascial cervical em dois ambientes: aquático e solo Comparative study of a protocol of manual therapy applied in patients with cervical myofascial pain syndrome in two environments: water and ground
}

Gardênia Márcia Macêdo da Costa*, Raimunda Hermelinda Maia Macena, D.Sc.**, Kalina Kelma Oliveira de Sousa, M.Sc.**, Cristiano Teles de Sousa, M.Sc.***, Teresa Maria da Silva Câmara, Esp..**, Vasco Pinheiro Diógenes Bastos, D.Sc. ${ }^{* * * *}$

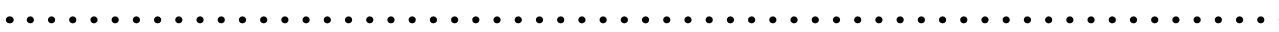

${ }^{*}$ Graduado Faculdade Integrada do Ceará (FIC), Fortaleza, Ceará, **Universidade Federal do Ceará (UFC), Fortaleza, Ceará, ***Faculdade Integrada do Ceará (FIC), Fortaleza, Ceará, ${ }^{* * *}$ Universidade Federal do Ceará (UFC), Faculdade Integrada do Ceará (FIC), Fortaleza, Ceará

\section{Resumo}

Síndromes Dolorosas Miofasciais Cervicais (SDMC) apresentam sintomatologia pouco definida e acometem músculos e fáscias, com presença dos pontos-gatilho miofasciais que podem originar dor característica, disfunção motora, diminuição da flexibilidade muscular, fraqueza muscular e alterar a propriocepção. Comparouse protocolo de terapia manual em pacientes com SDMC em dois ambientes: aquático e solo. Estudo exploratório, intervencional e longitudinal utilizou amostra de doze mulheres distribuídas em dois grupos $(n=6)$, entre agosto e outubro de 2007. O protocolo consistiu em 10 sessóes de terapia manual com acompanhamento no solo $(n=6)$ ou piscina $(n=6)$, atendidos pelo mesmo terapeuta. Os dados foram analisados através do MicroCall Origin 2.94. Ocorreu homogenia nos grupos. No solo havia aspectos que propiciavam melhor aplicação das técnicas. Na piscina a aplicação das técnicas foram menos eficientes, porém com maior grau de relaxamento global. As pacientes que desenvolveram senso-percepção da região cervical conseguiam relaxar durante a aplicação das técnicas, independente do ambiente, e obtiveram melhores resultados. Não houve diferença significativa entre o uso do protocolo no meio aquático ou solo. A propriocepção é um fator que contribui no aparecimento, manutenção e recidiva das cervicalgias devendo ser desenvolvida para evitar as crises de SDMC.

Palavras-chave: síndromes da dor miofascial, fisioterapia, hidroterapia.

\begin{abstract}
Cervical Myofascial Pain Syndromes (CMPS) have poorly defined symptoms and affect the muscles and fascia, with the presence of myofascial trigger points that can cause characteristic pain, motor dysfunction, decreased flexibility, muscle weakness and altered proprioception. We compared manual therapy protocol in patients with CMPS in two environments: water and ground. Exploratory study used longitudinal and interventional sample of twelve women divided into two groups $(n=6)$, between August and October 2007. The protocol consisted of 10 sessions of manual therapy with monitoring on the ground $(n=6)$ or swimming $(n=6)$, attended by the same therapist. Data were analyzed using the Origin MicroCall 2.94. The groups became homogeneous. The ground had aspects that provided better application techniques. In the pool the application techniques were less efficient, but with a greater degree of overall relaxation. The patients who developed sense-perception of the cervical region could relax during the application of techniques, regardless of the environment, and obtained better results. There was no significant difference between the use of the protocol into water or ground. Proprioception is a contributing factor in the onset, maintenance and relapse of neck pain and should be developed to avoid the crises of CMPS.
\end{abstract}

Key-words: myofascial pain syndromes, physical therapy, hydrotherapy. 


\section{Introdução}

A Síndrome Dolorosa Miofascial Cervical (SDMC) causada pela contratura do músculo trapézio é comum, principalmente em mulheres com idade entre 31 e 50 anos de idade [1-3]. A sintomatologia está intimamente relacionada a dores na região cervical que interferem diretamente na qualidade de vida no auge de atividade produtiva [4-7].

O tratamento fisioterápico está relacionado a técnicas utilizadas rotineiramente tais como: a inibição dos pontos gatilhos miofasciais, relaxamento muscular, liberação fascial, hidroterapia e eletro-foto-termoterapia [2,4,8-10]. Apesar do grande número de técnicas para tratar a cervicalgia, ainda existem controvérsias em relação ao melhor procedimento, principalmente no que se refere às diferenças entre as técnicas a serem aplicadas dentro e fora do meio aquático.

Diante disto, este estudo teve como objetivo geral comparar um protocolo de terapia manual aplicado em pacientes acometidos pela SDMC nos ambientes de solo e aquático.

\section{Material e métodos}

Este estudo de caráter exploratório, intervencional e longitudinal com estratégia de análise quantitativa foi realizado em uma clínica de Fisioterapia de atendimento exclusivamente particular e uma clínica-escola de Fisioterapia de uma instituição de ensino superior privada, ambas na cidade de Fortaleza/CE.

Participaram da pesquisa doze (12) mulheres que referiram dor na regiáo cervical e diagnóstico de Síndrome Dolorosa Miofascial Cervical, com prescriçáo médica (ortopedista) para tratamento fisioterápico. As mulheres foram distribuídas aleatoriamente em dois grupos (G1 - solo; G2 - meio aquático) e aceitaram participar mediante assinatura de TCLE. Foram excluídos indivíduos com diagnóstico de fibromialgia, portadores de distúrbios emocionais, cardiopatias, diabetes, doenças neurológicas, hidrofobia ou outras complicaçôes inerentes à água.

A coleta de dados ocorreu entre agosto e outubro de 2007, após aprovação do projeto pelo CEP/FIC (Faculdade Integrada do Ceará - sob o protocolo 024/07). Inicialmente, era procedida a avaliação fisioterapêutica e a seguir foi aplicado um protocolo previamente definido.

O protocolo consistiu na aplicaçáo de técnicas de terapia manual (liberação fascial, pompage, massagem superficial e profunda, inibição dos pontos gatilhos de dor e alongamento muscular), respeitando a dor e a limitação da contratura muscular na ocasião da sessão. A execuçáo do protocolo para cada indivíduo foi de dez dias, cinco vezes por semana, durante quarenta minutos e executado pelo mesmo terapeuta.

O protocolo em solo consistiu em manter o paciente em decúbito dorsal com membros inferiores estendidos e separados em nível do quadril, membros superiores ao longo do corpo com a palma das mãos voltadas para cima. Em seguida foi realizada a mobilização global da fáscia, pompage global, pompage dos escalenos, do trapézio superior, do elevador, sobre as rotaçóes e do esternocleido-occipito-mastóideo [8], massagem profunda e inibição dos pontos gatilhos de dor dos músculos da coluna cervical [4]. Após inibição e eliminação dos pontos gatilhos de dor, a inibição foi substituída por alongamento muscular.

No meio aquático, o paciente foi colocado em flutuação com apoio de flutuadores e pés fixados na barra da piscina para facilitar a aplicação das técnicas. A cervical foi constantemente sustentada pelas mãos do fisioterapeuta para facilitar a manipulação e evitar contratura dos músculos da região de cabeça e pescoço. Foram utilizados protetores auriculares para restringir o receio de ocupação do pavilhão auditivo por água e assim possibilitar o relaxamento da musculatura cervical.

As variáveis estudadas consistiram em pontuação da gravidade da contratura, nível de dor (escala analógica de dor [11]), pontos gatilhos, postura, grau de insatisfação na piscina, grau de amplitude de movimento e limitaçóes. A identificação dos pontos dolorosos foi mediada pelo uso da ficha de identificação proposta por Kostopoulos \& Rizopoulos [4]. Para analisar a qualidade do sono, foi solicitado às pacientes que atribuíssem o adjetivo que julgassem mais adequado para descrever sua qualidade de sono atual; a cada adjetivo foi atribuído um valor crescente - péssima (1), ruim (2), regular (3), boa (4) e ótima (5).

Os dados do estudo foram digitados pelo Epi Info, versão 6.04d do Center for Disease Control and Prevention e analisados pelo MicroCall Origin 2.94. Para a análise bivariada empregaram-se os testes de Pearson e exato de Fisher, para proporçốes e teste $\mathrm{t}$ (se paramétricas), e Wilcoxon (se não paramétricas) para variáveis contínuas, $\mathrm{p}<0,05$.

\section{Resultados}

A amostra era composta por mulheres jovens (G1 - 66,7\% com idade inferior a 41 anos e G2 - 51,1\% com idade inferior a 41 anos) e não possuíam união estável (G1 = 83,3\% x G2 $=66,7 \%)$. Embora a média de idade do G1 fosse superior ( édia $=36,66 \pm 6,25)$ à do G2 (média $=35,16 \pm 4,70)$ não se observou diferença estatisticamente significante entre eles ( $\mathrm{p}$ $=0,28)$. A atividade desencadeante da dor estava relacionada ao uso de computadores isolado ou associado ao estresse nos dois grupos (G1 e G2 = 66,7\%). Náo foi observada diferença no que se refere à qualidade do sono $(\mathrm{p}=0,72$ e $\mathrm{p}=0,72$, respectivamente) ou ao alinhamento da cabeça pré e pósprotocolo $(\mathrm{p}=0,72 \mathrm{e} \mathrm{p}=0,50$, respectivamente) (Tabela I).

Em relação à dor referida, observou-se que o nível médio da dor do G1 foi inferior (moderado $=83,3 \%$; média $=5,83$ $\pm 0,83$ ) ao do G2 (intensa $=50,0 \%$; média $=7,5 \pm 1,11$ ) . Após a realização do protocolo, observou-se redução estatisticamente significante da dor intragrupo, sendo maior no G2 $(\mathrm{G} 1-$ média $=0,33 \pm 0,21 ; \mathrm{p}<0,001$ e G2 - média $=1 \pm$ $0,81 ; \mathrm{p}<0,005)$. Entretanto, não foi evidenciada diferença significativa entre os grupos $(\mathrm{p}=0,63)$ (Tabela II). 
Tabela I - Dados sócio demográficos da amostra por grupo de intervenção. Fortalezal CE, 2007.

\begin{tabular}{|c|c|c|c|}
\hline Variáveis & $\begin{array}{c}\text { Grupo } 1 \\
\text { Fa (\%) }\end{array}$ & $\begin{array}{c}\text { Grupo } 2 \\
\text { Fa (\%) }\end{array}$ & $\begin{array}{l}\text { Valor } \\
\text { de P }\end{array}$ \\
\hline Faixa etária & & & 0,28 \\
\hline $17 \bullet \multimap 25$ & $1(16,7 \%)$ & $1(16,7 \%)$ & \\
\hline $25 \bullet-33$ & $2(33,3 \%)$ & $1(16,7 \%)$ & \\
\hline $33 \bullet-41$ & $1(16,7 \%)$ & $1(16,7 \%)$ & \\
\hline $41 \bullet-49$ & $0(0,0 \%)$ & $2(33,3 \%)$ & \\
\hline $49 \bullet-\bullet 56$ & $2(33,3 \%)$ & $1(16,7 \%)$ & \\
\hline Estado civil & & & 0,50 \\
\hline União estável & $1(16,7 \%)$ & $2(33,3 \%)$ & \\
\hline Sem união estável & $5(83,3 \%)$ & $4(66,7 \%)$ & \\
\hline $\begin{array}{l}\text { Atividade desencadeante } \\
\text { da dor }\end{array}$ & & & 0,53 \\
\hline Computador & $1(16,7 \%)$ & $1(16,7 \%)$ & \\
\hline Computador + estresse & $3(50,0 \%)$ & $1(16,7 \%)$ & \\
\hline Estresse & $2(33,3 \%)$ & $3(50,0 \%)$ & \\
\hline Não Sabe & $0(0,0 \%)$ & $1(16,7 \%)$ & \\
\hline $\begin{array}{l}\text { Qualidade do sono pré- } \\
\text { protocolo }\end{array}$ & & & 0,72 \\
\hline Bom & $4(66,7 \%)$ & $4(66,7 \%)$ & \\
\hline Ruim & $2(33,3 \%)$ & $2(33,3 \%)$ & \\
\hline $\begin{array}{l}\text { Qualidade do sono após } \\
\text { protocolo }\end{array}$ & & & 0,72 \\
\hline Bom & $4(66,7 \%)$ & $4(66,7 \%)$ & \\
\hline Ruim & $2(33,3 \%)$ & $2(33,3 \%)$ & \\
\hline $\begin{array}{l}\text { Postura da cabeça pré- } \\
\text { protocolo }\end{array}$ & & & 0,72 \\
\hline Alinhada & $2(33,3 \%)$ & $2(33,3 \%)$ & \\
\hline Alterada & $4(66,7 \%)$ & $4(66,7 \%)$ & \\
\hline $\begin{array}{l}\text { Postura da cabeça após } \\
\text { protocolo }\end{array}$ & & & 0,50 \\
\hline Alinhada & $4(66,7 \%)$ & $3(50,0 \%)$ & \\
\hline Alterada & $2(33,3 \%)$ & $3(50,0 \%)$ & \\
\hline
\end{tabular}

As regiôes dolorosas referidas antes do protocolo diferem entre G1 (dorso $=66,7 \%)$ e G2 (dorso e pescoço $=$ 66,7\%), sem diferença estatisticamente significante entre elas $(\mathrm{p}=0,28)$. Após a realização do protocolo, a eliminação da dor entre G2 (100,0\%) foi maior que entre G1 $(33,3 \%)$, com diferença evidenciada entre os grupos $(\mathrm{p}=$ $0,05)$ (Tabela II).

Os pontos gatilhos antes do protocolo do G1 (100,0\% no músculo levantador da escápula isolado ou associado a outro músculo) diferem estatisticamente de G2 (100,0\% no músculo trapézio superior isolado ou associado a outro músculo). Ao final do procedimento, houve a manutenção dos pontos gatilhos de G2 (33,4\% no músculo trapézio superior isolado ou associado a outro músculo) e modificação no G1 (33,4\% no músculo trapézio superior isolado ou associado a outro músculo e 16,7\% nos músculos escalenos), sem detecção de diferença estatística (Tabela II).
Tabela II - Dados relativos à postura e dor da amostra por grupo de intervenção. Fortalezal CE, 2007.

\begin{tabular}{|c|c|c|c|}
\hline Variáveis & $\begin{array}{l}\text { Grupo } 1 \\
\text { Fa (\%) }\end{array}$ & $\begin{array}{c}\text { Grupo } 2 \\
\text { Fa (\%) } \\
\end{array}$ & $\begin{array}{l}\text { Valor } \\
\text { de P }\end{array}$ \\
\hline Intensidade de dor pré & & & 0,27 \\
\hline protocolo & & & \\
\hline Moderada & $5(83,3 \%)$ & $3(50,0 \%)$ & \\
\hline Intensa & $1(16,7 \%)$ & $3(50,0 \%)$ & \\
\hline $\begin{array}{l}\text { Intensidade de dor após } \\
\text { protocolo }\end{array}$ & & & 0,51 \\
\hline Sem Dor & $4(66,6 \%)$ & $4(66,6 \%)$ & \\
\hline Dor leve & $2(33,3 \%)$ & $1(16,7 \%)$ & \\
\hline Moderada & $0(0,0 \%)$ & $1(16,7 \%)$ & \\
\hline $\begin{array}{l}\text { Regiões dolorosas referi- } \\
\text { das pré protocolo }\end{array}$ & & & 0,28 \\
\hline Dorso & $4(66,7 \%)$ & $2(33,3 \%)$ & \\
\hline Dorso e Pescoço & $2(33,3 \%)$ & $4(66,7 \%)$ & \\
\hline $\begin{array}{l}\text { Regiões dolorosas referi- } \\
\text { das após protocolo }\end{array}$ & & & 0,05 \\
\hline Dorso & $3(50,0 \%)$ & $0(0,0 \%)$ & \\
\hline Dorso e Pescoço & $1(16,7 \%)$ & $0(0,0 \%)$ & \\
\hline Sem Dor & $2(33,3 \%)$ & $6(100 \%)$ & \\
\hline $\begin{array}{l}\text { Pontos dolorosos à palpa- } \\
\text { ção pré protocolo }\end{array}$ & & & 0,03 \\
\hline $\begin{array}{l}\text { MM Escaleno, Trapézio } \\
\text { superior e Levantador da } \\
\text { escápula }\end{array}$ & $1(16,7 \%)$ & $0(0,0 \%)$ & \\
\hline MM Levantador da escápula & $1(16,7 \%)$ & $0(0,0 \%)$ & \\
\hline $\begin{array}{l}\text { MM Levantador da escápu- } \\
\text { la, Trapézio }\end{array}$ & $0(0,0 \%)$ & $5(83,3 \%)$ & \\
\hline $\begin{array}{l}\text { Superior e Longo do } \\
\text { pescoço }\end{array}$ & & & \\
\hline MM Trapézio superior & $0(0,0 \%)$ & $1(16,7 \%)$ & \\
\hline MM Trapézio superior e & $4(66,6 \%)$ & $0(0,0 \%)$ & \\
\hline Levantador da escápula & & & \\
\hline $\begin{array}{l}\text { Pontos dolorosos à palpa- } \\
\text { ção após protocolo }\end{array}$ & & & 0,39 \\
\hline MM Escalenos & $1(16,7 \%)$ & $0(0,0 \%)$ & \\
\hline $\begin{array}{l}\text { MM Levantador da escápula } \\
\text { e Trapézio superior }\end{array}$ & $0(0,0 \%)$ & $1(16,7 \%)$ & \\
\hline MM Trapézio superior & $0(0,0 \%)$ & $1(16,7 \%)$ & \\
\hline MM Trapézio superior & $1(16,7 \%)$ & $0(0,0 \%)$ & \\
\hline MM Trapézio superior e & $1(16,7 \%)$ & $0(0,0 \%)$ & \\
\hline Levantador da escápula & & & \\
\hline Não & $3(50,0 \%)$ & $4(66,6 \%)$ & \\
\hline
\end{tabular}

\section{Discussão}

A globalização, o acesso à informatização no ambiente laboral e de lazer tem ampliado o risco de ocorrência de doenças dolorosas miofasciais, de aquisição de hábitos posturais inadequados e de alteração na qualidade de vida das pessoas. A contratura muscular da região cervical e dorsal está intimamente relacionada ao estresse e a fadiga muscular $[2,6]$, 
principalmente entre mulheres [3], como as deste estudo, que tendem a possuir dupla jornada de trabalho e, com isto, ao final do dia apresentam períodos de exacerbação da dor.

Neste estudo, houve redução na média de dor pela análise da escala analógica visual, após a terapia em ambos ambientes. A detecção de regióes dolorosas miofasciais dorsais e cervicais (trapézio superior e levantador da escápula) nos dois grupos corroboram os achados de Corrigan e Maitland [12] e de Seó et al. [6] que apontam a constância da dor na síndrome dolorosa miofascial cervical, em especial na regiáo inter-escapular sendo comumente associada à rigidez, desencadeando o ciclo vicioso de dor-contração-dor e com isto a formação de pontogatilho conforme destacam Ruiz et al. [5].

$\mathrm{Na}$ execução da terapia no solo observa-se melhor aplicabilidade da terapia manual nas doenças dolorosas, conforme destacado por Bressan et al. [13] ao analisarem a aplicabilidade da terapia de alongamento na fibromioalgia. A estabilidade do solo permite que as manipulaçóes sejam executadas de forma precisa, com melhor controle sobre a respiração, atividade importante para a pompage e fundamental para o relaxamento. A redução da intensidade da dor, mas a não eliminação de todas as regiốes dolorosas e dos pontos gatilhos no grupo tratado no solo retrata o descrito por Hebert e Xavier [2] que afirmam que a dor desta síndrome nem sempre está localizada no músculo comprometido, podendo ser referida à distância e que os pontos-gatilhos podem ser latentes (não reconhecidos pelo paciente) ou ativos (percebidos pelo paciente).

Por outro lado, a eliminaçáo de todas as regióes dolorosas após protocolo observada no grupo tratado no meio aquático parece estar associada às propriedades da água como o favorecimento ao relaxamento muscular [7], o apoio da flutuabilidade e as forças hidrodinâmicas que interagem de forma a proporcionar um ambiente apropriado para as atividades de mobilidade [14]. Salvador $e$ t al. [15] relatam que vários estudos comparativos de terapia de solo, baseada em exercícios ativos livres e alongamentos passivos e programas de exercícios aquáticos de alongamento e relaxamento em pacientes portadores de fibromialgia demonstram melhora sintomatológica do grupo participante da hidrocinesioterapia mais significativa que a do grupo de solo.

Acrescente-se ainda que a permissibilidade de exercícios com diferentes graus de dificuldade no meio aquático ampliam a autoconfiança e adesão a esta terapia [15]. Do mesmo modo, a imersão em decúbito dorsal horizontal com a cabeça fora da água possibilita a redução do efeito da gravidade. Com isto, a diminuiçáo provoca um desvio de sangue e de líquido dos membros inferiores e do abdômen para a parte superior do corpo [16]. Com isto, o aumento da circulação na região cervical provocada pelo efeito da flutuação nos líquidos corporais proporciona a eliminação das substâncias causadoras da dor e favorece uma maior nutrição e oxigenação para os tecidos diminuindo a dor [11].

Apesar de os resultados descritos, é reconhecida como limitação a subjetividade na avaliação da dor e o desconhecimento do próprio corpo (propriocepção) pelos amostrados grupos de estudo. As pacientes que conseguiam relaxar durante a aplicação das técnicas, em solo ou no meio aquático, obtiveram melhores resultados que as pacientes que não conseguiam relaxar por falta de senso-percepção da região cervical.

Além disto, no meio aquático houve dificuldade para realizar as técnicas propostas com precisão, considerando que em flutuação o corpo não fica completamente estabilizado e a mão do terapeuta desliza mais facilmente no corpo molhado.

\section{Conclusão}

Embora existam diferenças na execução das técnicas de terapia manual no solo e no meio aquático estas não são suficientes para produzir heterogeneidade nos resultados da redução da sintomatologia dolorosa nas pessoas acometidas pela Síndrome Dolorosa Miofascial Cervical.

Apesar de no meio aquático ser possível se utilizar os efeitos da flutuabilidade, o que favorece o relaxamento, estes mesmos efeitos dificultam a aplicação das técnicas de terapia manual. Por outro lado, o uso do solo limita o relaxamento muscular intenso, assim a propriocepção torna-se um fator importante.

Deste modo, a propriocepção é uma ferramenta fundamental para prevenir o aparecimento da dor e promover o tratamento e prevenção de recidiva das cervicalgias devendo ser desenvolvida pelo fisioterapeuta para evitar/minimizar as crises de Síndrome Dolorosa Miofascial Cervical.

\section{Referências}

1. Barros Filho TEP, Basile Júnior R. Coluna vertebral: diagnóstico e tratamento das principais patologias. 1a ed. São Paulo: Sarvier; 1995.

2. Hebert S, Xavier R. Ortopedia e traumatologia: princípios e prática. 3a ed. São Paulo: Artmed; 2003.

3. López JF. Síndrome Miofascial Dolor en la mujer. Bogotá: ACED; 2008. p.181-196.

4. Kostopoulos D, Rizopoulos K. Pontos-gatilho miofasciais: teoria, diagnóstico, tratamento. Rio de Janeiro: Guanabara Koogan; 2007.

5. Ruiz VN, Fernández-Alcantud J, Hernández-Salván J, Riquelme I, Benito G. Dolor de origen muscular: dolor miofascial y fibromialgia. Rev Soc Esp Dolor 2007;1:36-44.

6. Seó RS, Campanha NH, Alencar Júnior FGP, Neppelenbroek $\mathrm{KH}$, Almilhatti H J. Dor miofascial e fibromialgia: de mecanismos etiológicos a modalidades terapêuticas. UEPG Ciências Biológicas e da Saúde 2007;13(1/2):39-51.

7. Bastos CC, Oliveira EM. Síndrome da fibromialgia: tratamento em piscina aquecida. Lato \& Sensu 2003;4(1): 3-5.

8. Bienfait M. As bases da fisiologia da terapia manual. 1a ed. São Paulo: Summus; 2000.

9. Koury JM. Programa de fisioterapia aquática: um guia para a reabilitação ortopédica. São Paulo: Manole; 2000.

10. Sprott $\mathrm{H}$. What can rehabilitation interventions achieve in patients with primary fibromyalgia? Curr Opin Rheumatol 2003;15(2):145-50. 
11. Torres DFM. Fisioterapia: guia prático para a clínica. Rio de Janeiro: Guanabara Koogan; 2006.

12. Corrigan B, Maitland GD. Transtornos musculoesqueléticos da coluna vertebral. Rio de Janeiro: Revinter; 2005.

13. Bressan LR, Matsutani LA, Assumpção A, Marques AP, Cabral CMN. Effects of muscle stretching and physical conditioning as physical therapy treatment for patients with fibromyalgia. Rev Bras Fisioter 2008;12(2):88-93.
14. Hall CM, Brody LT. Exercício terapêutico: na busca da função. Rio de Janeiro: Guanabara Koogan; 2001.

15. Salvador JP, Silva QF, Zirbes MCGM. Hidrocinesioterapia no tratamento de mulheres com fibromialgia: estudo de caso. Fisioter Pesqui 2005;11(1):27-36.

16. Ruoti RG, Morris DM, Cole AJ. Reabilitação aquática. 1a ed. São Paulo: Manole; 2000. 